\title{
Modelo de interacción entre el dibujo y las actividades sensomotrices (MIDAS): Fomentando la inteligencia espacial
}

Docente, diseñador gráfico y fotógrafo independiente, Costa Rica pedrocalvoguevara@gmail.com

\section{Resumen}

El ensayo fue motivado por la idea de aprovechar el efecto potenciador de la inteligencia espacial que promueve la interacción entre el dibujo y las habilidades visuales espaciales. La tríada percibir-visualizar-dibujar reúne capacidades motoras e intelectuales, en un proceso que favorece la información visual. El Modelo de interacción entre el dibujo y las actividades sensomotrices (MIDAS) define, explica y conecta esos ejes temáticos como un sistema que produce aprehensión del objeto y generación e integración de aprendizajes, mediante el desarrollo de habilidades físicas y mentales.

Se presenta el modelo, subrayando su valor como herramienta teórica, capaz de encauzar las innovaciones educativas en dos direcciones: desde el dibujo hacia el desarrollo de destrezas intelectuales o desde las habilidades visuales espaciales hacia el mejoramiento de la precisión en el dibujo y de la metodología de enseñanza.

Palabras clave: Psicología de la educación, cognición, inteligencia visual-espacial, actividad sensomotriz, dibujo.

\section{Abstract \\ Drawing and Sensorimotor Activities Interaction Model (MIDAS): Enhancing The Spatial Intelligence}

The essay was motivated by the idea of taking advantage of the enhancer effect that the relation between drawing and visual spatial ability has on the intelligence. The triad percieving-visualizating-drawing gathers both motor and intellectual skills in a process that favors visual information. The Drawing and Sensorimotor Activities Interaction Model (MIDAS) defines, explains and connects those topics as a system that produces object apprehension and generation-integration of learning while developing physical and mental skills.

The model is introduced, emphasizing its value as a theoretical tool, capable of leading educational innovation in two directions: from drawing towards intellectual skills enhancing or else focusing visual spatialespatial skills to improve drawing precision and teaching methodologies.

Keywords: Educational psychology, cognition, visual-spatial intelligence, sensorimotor activities, drawing. 


\section{INTRODUCCIÓN}

La inteligencia visual espacial, con su propio código simbólico formado por imágenes, es un componente de suma importancia en el desarrollo de las personas, al punto de ser considerado un eje del pensamiento equiparable al lingüístico y al lógico-matemático, con contribuciones innegables al pensamiento científico y artístico (Gardner, 2001).

La formación profesional, tanto en artes plásticas como en docencia, así como la experiencia como dibujante, motivó el interés científico sobre los campos de la inteligencia visual-espacial y del dibujo, con la intención de indagar la posibilidad de desarrollar la inteligencia visual-espacial, dibujando. La hipótesis de partida es que existe una relación de causa y efecto que favorece, mediante la actividad sensomotriz, el desarrollo recíproco del dibujo y la habilidad visual-espacial.

La revisión de literatura al respecto no permitió hallar investigaciones que describieran la relación de la habilidad visual espacial con el dibujo. Por ejemplo, Paz (2013) menciona que al dibujar se desarrolla "el pensamiento abstracto [y] la capacidad de formular ideas" (p.4), pero no elabora una argumentación que responda a la cuestión planteada anteriormente. Lo mismo sucede con Mujica (2012) al citar a Brites y Almoño quienes afirman que "el dibujo es también una técnica de pensamiento" (p. 157), sin embargo no se profundiza acerca de cómo, dibujando, se puede potenciar dicho ámbito de la inteligencia.

La clasificación de las destrezas, incluso su descripción, carecen de consenso entre quienes se consultaron. Mohler (2008) hace una reseña que incluye a Thorndike, Thurstone y Carrol, quienes evidencian posturas teóricas sobre la habilidad espacial, tan disímiles como que se trata de una inteligencia mecánica o un conjunto de habilidades como la memoria asociativa, la comprensión verbal o la habilidad para formar representaciones mentales de patrones visuales.

Por otra parte, de la propuesta de Maier y Tartre, citada por Sorby (1999); se extrae del primer autor mencionado el planteamiento de una habilidad espacial formada por cinco componentes (percepción, visualización, rotación mental, relaciones espaciales y orientación en el espacio); mientras del segundo, la propuesta de clasificar estas habilidades en dos categorías: visualización espacial y orientación espacial. En contraste, Bellido (2012) propone una jerarquía de habilidades espaciales donde el volumen y el espacio son fundamentales. Velázquez y León (2011) por su parte, colocan la habilidad para realizar creaciones visuales en la cima de una jerarquía diferente (p. 233).

Con base en lo anterior, la habilidad espacial puede describirse como un constructo fragmentario y su relación con el dibujo se muestra poco precisa. En respuesta a este vacío se presenta el Modelo de interacción entre el dibujo y las actividades sensomotrices (MIDAS) de Calvo (2016, pp. 39-66), el cual ordena los roles que las habilidades espaciales necesitan en el proceso de dibujar y explica sus relaciones.

Ha de aclararse, que en esta investigación se adopta la noción de inteligencia de Gardner (2001), quien toma en cuenta múltiples factores para su conformación. Además, cualquier referencia sobre ella está ubicada en el dominio de la inteligencia espacial, dentro del campo visual.

El término visual-espacial se utiliza, por tanto, para calificar el conjunto de habilidades que, de acuerdo con el autor citado, conforman la inteligencia espacial en el ámbito visual. De modo que los términos habilidad espacial y habilidades o capacidades espaciales son utilizados como sinónimos de la inteligencia visual espacial porque las aptitudes a las que se refieren se abordan en conjunto de manera general. Definiciones adicionales como las de visualización, percepción, son expuestas conforme avanza la argumentación, como parte de la elaboración que se hace del modelo MIDAS.

En otro estudio del autor (Calvo, 2016), se examinó el tema con el fin de explorar cómo desarrollar esa inteligencia en un grupo de adolescentes de noveno año de secundaria mediante un curso de dibujo a mano alzada, y se halló la necesidad de dilucidar el tipo de función de la actividad sensomotriz 
al dibujar. El MIDAS nació entonces como la base teórica de esa propuesta didáctica que considera el dibujo estratégicamente.

\section{DESARROLLO DEL TEMA}

\section{Proposición}

Se propone, mediante el MIDAS, que al percibir-visualizar-dibujar se aprehende el objeto y se estimula el pensamiento visual espacial, en un ciclo que muestra mayor y mejor cantidad de información visual. Además, se enfatiza sobre el potencial de la herramienta teórica en el campo de la educación y se llama a la discusión de sus implicaciones en la innovación de la metodología de dibujo y sobre la capacidad natural de la práctica para desarrollar la inteligencia visual-espacial.

Antes de abordar la versión revisada del constructo teórico, se debe aclarar la noción de información visual; para ello se procede a contrastarla con la de tipo verbal mediante un ejemplo. Considere el lector el ejercicio mental de imaginar la figura a la que se refiere el siguiente enunciado: este es un segmento circular igual a media circunferencia de radio $r=x$, girado 45 grados en sentido de las manecillas del reloj. La figura se cierra con curvas suaves que se conectan con otro segmento circular igual a un cuarto de circunferencia, de radio $r_{2}=x / 2$ ( $x$ dividido entre 2), trazado en dirección opuesta al primero, cuyo centro está a una distancia $x$ del centro del primer arco, sobre un eje inclinado a 45 grados hacia el extremo inferior izquierdo.

La figura 1 muestra el contorno descrito.

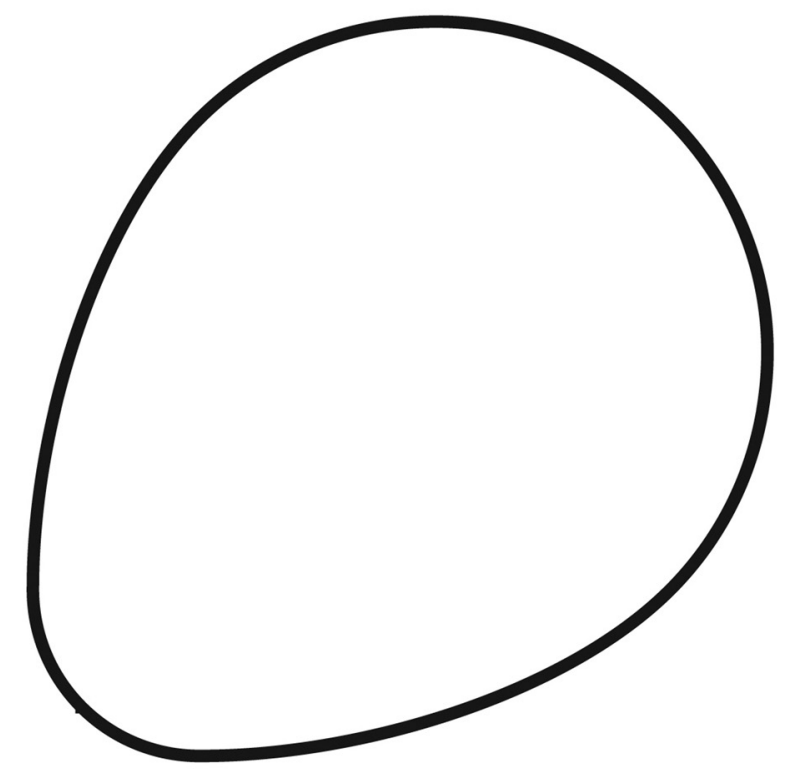

Figura 1. Contorno descrito en el ejemplo introductorio. Fuente: Calvo (2016).

Para muchas personas resultaría difícil imaginarlo y aunque es posible ofrecer más detalles que mejoren la precisión de la descripción verbal, por ejemplo al referirse a "curvas suaves", se advierte que describir verbalmente un contorno sencillo impone serias demandas. Al ver la figura 1 desaparecen las dificultades propias del lenguaje que surgen cuando se intenta reemplazar con palabras el fenómeno visual. La imagen, en cambio, se manifiesta con exquisita inmediatez. 
La razón por la que resulta sencillo comprender aquello que es explícito a la vista es que las personas están dotadas de inteligencia visual espacial, descrita por Gardner (2001) como un conjunto de capacidades relacionadas que comprende, entre otras, "la habilidad para reconocer instancias del mismo elemento; la habilidad para transformar o reconocer una transformación de un elemento en otro; la capacidad de evocar la imaginería mental y luego transformarla" (p. 142). Las habilidades se clasifican en dos grandes grupos: de percepción y de visualización. Esas dos categorías son los ejes temáticos de la disertación junto a un tercer factor en la "ecuación psicomotriz", el dibujo.

\section{Argumentos para la discusión: Modelo de interacción entre el dibujo y las actividades sensomotrices, MIDAS}

McKim (citado por Sorby, 1999) aporta un punto de partida para esta argumentación al explicar que el pensamiento visual es conducido por tres tipos de imaginería mental combinados: ver, imaginar y dibujar. Se empieza a distinguir así un ciclo de realimentación del pensamiento que el modelo presentado toma como punto de partida, sin ahondar en los argumentos del autor, ya que se reinterpreta la triada, a la luz de varios postulados teóricos y de la inclusión de factores y productos que, se estima, participan en el sistema y lo transforman. La nueva propuesta, denominada MIDAS, redefine los tres factores como percibir, visualizar y dibujar.

Esta es una herramienta teórica, donde se propone una explicación de cómo se enlazan las actividades motoras con aquellas habilidades visuales de la inteligencia espacial. El modelo ordena una progresión de actividad motriz e intelectual que al integrarse van dando paso a aptitudes más complejas llamadas habilidades superiores, las cuales representan una vía de desarrollo de las habilidades visuales espaciales y del dibujo.

Es un modelo constructivista pues apela a la construcción de conocimiento y a la interpretación de la realidad a través de la formación de ideas por medio de la visualización, en interacción con el medio circundante desde la percepción y el dibujo.

EI MIDAS se esquematiza gráficamente más adelante en la figura 2, pero se recomienda leer los apartados siguientes antes de observar la imagen, pues se refieren justamente a cada uno de los conceptos que se muestran gráficamente, mediante los cuales se elabora una argumentación teórica que los respalda.

\section{El factor dibujar}

La palabra dibujo puede confundirse con el producto, la disciplina o la técnica; en consecuencia y para ser más precisos, este concepto se toma como indicador de un tipo de acción ubicada en el contexto de la actividad sensomotriz. El concepto de dibujo se despoja de toda referencia a la representación, con el fin de evitar la confluencia de discusiones propias de la teoría del arte, la filosofía o la estética.

Dibujar, entonces, se define desde un sentido materialista, como el acto de trazar representaciones gráficas (figuras o signos) en dos dimensiones, con movimientos voluntarios, utilizando un material que impregne la superficie contra la que se presiona, con la mano $u$ otra parte del cuerpo.

El sentido materialista de esta definición pretende recalcar varios aspectos importantes: que al dibujar existe representación gráfica con un grado mínimo de objetividad, sin importar el significado que se le pueda agregar; que es intencional sea cual sea la motivación por la que se realiza, es decir, que los trazos son encauzados hacia el logro de dicha representación; que esta se interpreta desde las dos dimensiones aunque represente algo tridimensional y, lo que es más significativo en un contexto educativo, 
permite a la mayoría de personas la posibilidad de participar del dibujo sin limitaciones en el uso de materiales y superficies no tradicionales.

\section{El factor percibir}

La imagen producida por efecto del impacto de la luz sobre la retina permite a las personas ver. La idea es insuficiente a la hora de hablar de percepción visual porque ha de considerarse el proceso mental o intelección que se produce y que es más complejo que el solo hecho de ver. Las personas pueden mirar una misma imagen $y$, sin embargo, percibirla de diferentes maneras.

Desde la teoría Gestalt de inicios del siglo XX, Koffka (1922) otorga a la imagen un carácter de sensación y confiere a esta última un sentido de unidad compuesta por muchos elementos, un "manojo" de estímulos-sensaciones influenciados por el principio gestáltico de asociación.

Durante el proceso de percepción, la coexistencia de múltiples estímulos con el potencial de conformarse en una imagen puede desencadenar la reproducción de uno o más modos de ver una imagen frente a los mismos estímulos y se admite, además, que la sensación no es solo una función del estímulo; se introduce así el concepto de atención como aquello que determina cuál sensación posible se va a establecer.

El concepto de atención adquiere un papel preponderante durante la percepción debido a que, a diferencia de los estímulos externos que pueden determinar la calidad e intensidad de la sensación, la atención afecta la claridad o el grado de consciencia. Se trata, entonces, de un factor que puede ser consciente y, por ello, controlable, lo que puede potenciar el análisis que se haga de un objeto y favorecer su aprehensión.

Una vez explicados estos principios, Koffka (1922) completa su exposición sobre la Gestalt con lo que llamó estructura: un estar listo para un cierto modo de respuesta del organismo frente a un estímulo. Entre las principales estructuras descritas por el autor, se encuentra la figura-fondo, donde la figura aparece siempre sobre un fondo y es de percepción inmediata, pudiéndose dar en cualquier campo sensorial ya sea visual, auditivo o de otro tipo.

De manera similar al fenómeno de figura-fondo, Wertheimer (1923) analiza otros principios (que aquí solo se van a mencionar) por los cuales se explica la percepción de ciertos arreglos y divisiones de estímulos, como los factores de proximidad, similitud, dirección y el hábito, entre otros.

En 1998, cuando ya la teoría de las inteligencias múltiples de Gardner llevaba más de una década, Hoffman (2000) retoma el concepto de inteligencia visual y profundiza en él desde una perspectiva constructivista que evidencia otras influencias que no poseían los gestaltistas.

Para Hoffman (2000), percibir implica una intelección que dista mucho de ser pasiva. Los gestaltistas llamaron a este tipo de intelección fenómeno óptico (estímulo-respuesta), desde la tradición conductista imperante en su época; mientras que Hoffman lo redefine como construcción.

De acuerdo con este autor, ver algo no es solo estar en presencia o interacción con él y tener la posibilidad de verlo en un sentido relacional; también puede interpretarse desde un sentido fenoménico como la forma en que las cosas parecen ser (Hoffman, 2000).

Asimismo, Hoffman menciona que el acto de percibir se realiza de manera casi instantánea y, lo que es más importante, gracias al proceso se construyen mundos visuales útiles, basados en imágenes en el ojo, dibujadas en dos dimensiones sobre sus tejidos sensibles, por lo que la interpretación del mundo en tercera dimensión (3D) es una construcción, entre innumerables posibilidades; la más útil para quien observa. Esta cualidad de utilidad, en las construcciones o intelecciones visuales, es lo que transforma el concepto de percepción de Hoffman. 
El estudioso compara el fenómeno perceptivo con un genio creativo muy completo, que aparece sin esfuerzo, pero que construye de acuerdo con principios reunidos en lo que llamó reglas de la visión universal o reglas de procesamiento visual (Hoffman, 2000). Son una explicación de cómo el cerebro interpreta automáticamente lo que ve. No se pretende entrar en el detalle de cada una de ellas, el objetivo de este apartado es solo mencionarlas para ofrecer una visión general del fenómeno de la percepción, recalcando el hecho de que existe todo un proceso de intelección implicado.

Algunos enunciados provenientes de las reglas de Hoffman (2000) indican: una línea recta en una imagen se interpreta siempre como una línea real en 3D (p.27), o bien, que una curva que es suave en una imagen es interpretada siempre como suave en las tres dimensiones (Ibíd., p. 34) y que una unión en $\mathrm{T}$ (cabeza y tronco) en una imagen se interpreta como el punto donde el canto completo se oculta a sí mismo (Ibíd., p. 39). Sus reglas describen un proceso de intelección que permite la interpretación del volumen de una figura y hace posible, por ejemplo, que se perciba la sensación tridimensional al observar siluetas planas.

Con las reglas descritas por Hoffman, más las propias de la perspectiva, se explica un proceso perceptivo por el cual la inteligencia construye el mundo visual que las personas miran. Además, como el proceso parte de una imagen en dos dimensiones (fijada en la retina) para construir un mundo visible tridimensional, se explica por qué es posible dibujar e interpretar los trazos resultantes como representaciones de cosas.

Con la argumentación hasta aquí planteada se empieza a dilucidar la relación entre percibir y dibujar. La superficie sobre la que se dibuja es como el tejido retiniano sobre el que se fija la imagen en dos dimensiones de lo que se mira; la inteligencia visual construye la percepción de tridimensionalidad desde allí.

En el caso del dibujo, quien realiza el trazo ya no es la luz sobre la retina, sino la persona sobre el lienzo. Lo anterior supone un problema por resolver: recodificar la construcción tridimensional de la escena u objeto percibido, traduciéndola al lenguaje de las dos dimensiones por medio de los trazos dibujados; para ello deberá emplearse la acción motora en estrecha relación con la intelección visual.

A manera de ilustración, al mirar una manzana, la luz forma instantáneamente un dibujo retiniano que se pone a disposición de la inteligencia visual y permite el percibir. Viendo un dibujo inconcluso de esa manzana, se debe emplear la percepción en función del acto de dibujar para terminarlo. Además, como cada trazo es también objeto de percepción, el enlace entre percibir y dibujar resulta ineludible.

El hecho de que percibir y dibujar vayan de la mano es bastante obvio, lo que se busca aquí es argumentar que el dibujar es un acto inteligente $y$, lo que no es tan obvio, que practicarlo fomenta la inteligencia visual espacial. No obstante, la argumentación no está completa sin que antes sea abordado otro ámbito de la inteligencia capaz de, entre otras cosas, recrear y manipular el volumen y el espacio y, al hacerlo, puede prescindir de referencias o fuentes externas a la persona, como la misma luz o la presencia de objetos. Se trata del tercer factor: la capacidad de visualizar.

\section{El factor visualizar}

La visualización ha sido explicada de maneras disímiles, según quien la mencione. Además, varios términos han sido utilizados por diferentes investigadores e investigadoras de la habilidad espacial (visualizar, visualización, imaginar, visualización mental) para describir una misma acción: evocar una imagen en la mente. En el presente estudio se hace referencia a la acción de visualizar como un acto implicado en cualquier categoría en la que se hable de habilidad visual espacial.

Tómese nuevamente como ejemplo el dibujo de una manzana; así como al trazar se va construyendo una representación gráfica de esta, al visualizar se construye una representación mental: la fruta adquiere otra identidad, ahora pertenece al grupo de las imágenes mentales. 
Esta representación visual interna puede ser, de acuerdo con Newell, Shaw y Simon (1958), espejo de todas las propiedades relevantes de la representación externa. En otras palabras, la información obtenida de una imagen generada en el interior de la mente es comparable a la de una imagen percibida de un objeto externo. Para estos autores, que una representación interna sea visual implica poder desencadenar en la mente procesos equivalentes de información a aquellos que operan sobre las representaciones internas de las experiencias sensoriales directas.

Los productos de la visualización mental (imágenes mentales) pueden servirles a las personas tanto como la visión de modelos reales para procesar información de ellos, con la ventaja de poder ser evocadas sin la presencia física de los objetos a los que se refieren o, incluso, representar objetos que no existen en la realidad física.

Los autores en cuestión describen la inteligencia implicada aquí como el ojo de la mente o "mind's eye" (Newell et al., 1958, p. 55) que produce fenómenos de imaginación visual. Esta metáfora recuerda al genio creativo de Hoffman, que construye instantáneamente lo que se mira y, gracias a él, se puede percibir el mundo físico e interactuar allí. En contraste, el ojo de la mente construye imágenes que en principio no son para actuar en el mundo físico, sirven para analizarlo de manera consciente. Con base en lo anterior, el presente documento coloca las imágenes mentales en el plano de las ideas y no en el de las percepciones.

Por otra parte, se utiliza el término "visualizar" porque se prefiere un significado aumentado del concepto de imaginar, que incluya un proceso de ideación visual y subraye el hecho de que se abstrae información y que así se puede acelerar la generación de soluciones a los problemas, por la abstracción del detalle (Newell et al., 1958).

El proceso de generación de soluciones por abstracción lo explican los autores citados, indicando que, cuando se codifica información de modo que sea accesible a los procesos visuales, se integran automáticamente a esa codificación todas las relaciones implícitas en los procesos de información, pero, además, que el ojo de la mente no solo es utilizado para procesar formas visuales de la naturaleza, sino que a menudo deliberadamente se construyen representaciones visuales de relaciones abstractas (Newell et al., 1958, pp. 55-56).

El pensamiento creativo se describe como una manera de solucionar problemas que incluye la acción de abstraer dentro de sus principales principios. Visualizar, entonces, sería una vía para la potenciación de la creatividad y una herramienta básica para el dibujo.

Llegado este punto, es de rigor un paréntesis para observar la teoría de Piaget, quien investigó las imágenes mentales, colocándolas dentro de la maquinaria de desarrollo intelectual.

Para Piaget (1969), las imágenes mentales fungen como instrumentos de conocimiento subordinados a los aspectos operativos del pensamiento, no antes de los siete u ocho años de edad, debido a que en los estados pre-operatorios anteriores, la imagen es "estática y reproductora, sin posibilidad de anticipar los movimientos o el resultado de las transformaciones" (p. 20).

No es sino hasta que aparecen las funciones semiótica y simbólica que en la niñez es posible darle un significado al dibujo en representación de una persona u objeto físico. El dibujo y la imagen mental son, en esta etapa, una imitación de lo real, explica el autor. Es por ello que Piaget e Inhelder (1997) llaman a la imagen mental imitación interiorizada, considerándola una copia activa de los cuadros perceptivos y distinguiendo entre dos categorías de imágenes mentales: las reproductoras, que evocan espectáculos ya percibidos; y las anticipadoras, que imaginan movimientos, transformaciones y sus resultados, sin haberlos presenciado antes (p. 76-77). 
Las imágenes anticipadoras posibilitan varias habilidades relevantes para la investigación, como el permitir a las personas (desde los nueve y diez años de edad) anticipar por el dibujo la forma de un objeto que ha de ser trazado, tal como sería visto por un observador desde otra posición, el fenómeno conocido como descentración.

Piaget (1969) acepta que las imágenes mentales son parte integral del desarrollo del pensamiento y menciona que las imágenes cinéticas y de transformación son "imágenes propiamente mentales" (p. 79) porque son parte y producto de un proceso inteligente.

La objeción que en el presente trabajo se hace al planteamiento de Piaget es que, en lo referente a visualización mental, el proceso inteligente involucrado tenga que adaptarse necesariamente a un modelo lógico-matemático. Se prefiere la idea de un ámbito propio para estos procesos mentales, desde una perspectiva multifactorial de la inteligencia que otorgue a las imágenes mentales y a la capacidad de visualizar, una función mucho más amplia que la de imitación.

\section{El ámbito visual de la inteligencia espacial}

En su teoría de las inteligencias múltiples, Gardner (2001) se opone a la idea de explicar la inteligencia como una gran facultad general y a la centralidad de las aptitudes lógico-matemáticas del modelo piagetiano. Gardner infiere conocimiento espacial, en sus fases activas y estáticas, desde la distinción planteada por Piaget de imágenes mentales reproductoras y transformadoras o anticipadoras. Para Gardner estas formas de conocimiento deben ser consideradas parte de una inteligencia y evidencian que el conocimiento visual-espacial se representa en un sistema simbólico diferente al lógico-matemático.

El autor agrega: "En los seres humanos normales, la inteligencia espacial está íntimamente relacionada con la observación personal del mundo visual y crece en forma directa de ésta" (Gardner, 2001, p. 141), lo cual no significa que la inteligencia espacial dependa del todo de la vista. Entre sus habilidades están "las capacidades para percibir con exactitud el mundo visual, para realizar transformaciones y modificaciones a las percepciones iniciales propias, y para recrear aspectos de la experiencia visual propia, incluso en ausencia de estímulos físicos apropiados" (Ibíd.).

Para el autor, los problemas visual-espaciales requieren explícitamente la construcción de una imagen mental y resulta elemental la inteligencia visual como la describe Hoffman, resumida en el apartado anterior; no obstante, se admite un proceso cognitivo que Thurstone explica al considerar que, gracias a la percepción, se puede interpretar una vista de un objeto, pero es mediante la inteligencia espacial que se puede reconocer su identidad cuando se le observa desde otros ángulos (Gardner, 2001).

Las habilidades descritas solo comienzan con la percepción, pero no terminan con la evocación de una imagen; adicionalmente, se puede manipular la imagen de forma similar a como se haría con objetos reales. Si en la realidad física un objeto se puede transformar, lo mismo se puede hacer mentalmente si primero se visualiza.

Con lo expuesto, se argumenta que durante la acción de visualizar, traer a la mente una imagen es el punto de partida de cualquier otra acción mental que se haga con ella y forma parte de un proceso de ideación visual que involucra habilidades espaciales del ámbito visual, tales como trasladar su posición o la de alguna de sus partes, transformarla, multiplicarla o hacerla girar sobre cualquier eje imaginario (rotación mental); todas ellas son acciones que podemos catalogar como modificación mental, incluyendo la vista de un objeto visualizado desde otro ángulo, como una manera de modificarlo.

Por ello, dentro del ámbito visual de la inteligencia espacial, en este estudio se denomina a todas estas capacidades habilidades de visualización, enfatizando en su utilidad para analizar el objeto visualizado. 
La descripción de Hoffman (2000) sobre los procesos visuales, puede hacer pensar que la percepción es una forma de visualización, quizás la más completa de todas, debido a la construcción que lleva a cabo el intelecto a la hora de percibir. Sin embargo, se considera que los procesos perceptivos tienen un lugar propio dentro de la inteligencia visual espacial porque, aunque están ligados directamente a la visualización, funcionan frente al mundo físico externo, para interpretarlo pero no para analizarlo.

Aquí se llama habilidad visual espacial de percepción al conjunto de capacidades intelectuales que contribuyen a crear una imagen mental de un objeto en presencia de este y a través de la visión, es decir, involucrando la intelección perceptiva. Entre las capacidades involucradas, se pueden citar las de identificar formas y entender los volúmenes de los objetos y las relaciones espaciales entre sus partes (proporciones) o entre un conjunto de objetos, además de otras cualidades físicas visuales como el color y la textura.

De tal manera que las habilidades visuales espaciales se clasifican según sean de percepción o de visualización. Como se explicó con anterioridad, las habilidades que actúan al percibir ayudan a comprender visualmente un objeto, mientras que las segundas intervienen cuando se intenta modificar mentalmente la imagen visualizada de un objeto.

Por su parte, la acción de dibujar, tal como se definió en este capítulo, es desarrollada por la destreza motora. Lo que muestra de visual-espacial este acto, y por lo cual se califica como inteligente, se explica desde su interacción con habilidades mentales, en este caso visualizar y percibir. El cuadro 1 muestra el tipo de acciones que corresponden a cada categoría de habilidad visual espacial.

CUADRO 1

Acciones que corresponden a cada categoría de habilidad visual espacial

\begin{tabular}{ll}
\multicolumn{1}{c}{ Capacidades de percepción } & \multicolumn{1}{c}{ Capacidades de visualización } \\
\hline Identificación de formas & Modificar la imagen visualizada mediante: \\
Interpretación de volúmenes & Rotación \\
Comprensión del espacio & Traslación y \\
Reconocimiento de relaciones espaciales & Transformación mental \\
\hline
\end{tabular}

Fuente: elaboración propia.

Cabe preguntarse: ¿cómo se podrían definir las interacciones visualizar-percibir; dibujar-percibir y la que corresponde a visualizar-dibujar? Las capacidades que se observan son habilidades superiores, puesto que integran varias clasificaciones que se analizan en las siguientes páginas.

Estas habilidades integradas deben ser consideradas, también, habilidades para el dibujo pues cualquier persona que se encuentre en condiciones físicas normales y con un mínimo de destreza motora que le permita hacer trazos en concordancia con la definición materialista de dibujar que se planteó anteriormente, lo puede hacer, pero el grado de pericia que desarrolle en esta práctica depende directamente de las integraciones. Al mismo tiempo, con este argumento se pretende demostrar que al dibujar se estimulan las habilidades espaciales sin importar el grado de pericia para hacerlo. 


\section{Habilidades espaciales superiores o de integración}

\section{Integraciones con el factor dibujar}

Los investigadores y teóricos de la habilidad espacial citados en este apartado reconocen dos conceptos claves que describen precisamente la integración respectiva de los factores visualizar y percibir con la acción de dibujar.

Según estos autores, la coordinación visual-motora involucra el control de pequeños movimientos de los dedos, mientras que la integración visual espacial implica crear una representación mental de una imagen y replicarla con pequeños movimientos musculares (Carlson Rowe y Curby, 2013). La integración visual espacial es lo que une el acto de dibujar con las habilidades espaciales de visualización.

De la descripción anterior se desprenden varias ideas; por una parte se involucra la acción motora muscular general y de los dedos, por lo que se le llamará integración espacial- motora y no visual-espacial, precisamente para enfatizar esa relación directa con la capacidad motora.

Por otra parte, la acción de trazar el dibujo de una figura sería un producto de esa integración y de coordinación: en el dibujo se expresan ambas habilidades que, a su vez, nutren el acto de dibujar. La coordinación visual-motora y la integración espacial-motora están a medio camino entre las intelecciones de las que parten y la acción que las conduce, mientras que el dibujo es un producto directo de estas habilidades.

\section{Integración percibir-dibujar: Coordinación visual-motora}

La coordinación visual motora es una habilidad superior que integra las destrezas motoras con las habilidades de la percepción y durante la acción de dibujar sincroniza lo mirado con el movimiento físico necesario para trazarlo. Actúa en presencia del objeto percibido en función de la acción de dibujarlo, utilizando herramientas de verificación-corrección del trazado y en función del dibujo mismo como fuente de realimentación visual, aun sin la presencia del objeto.

Para ejemplificar lo anterior, supóngase que se dibuja de nuevo la manzana; la coordinación visual-motora permite, una vez que se observó la manzana, coordinar el movimiento de su mano para que el dibujo vaya correspondiéndose con la realidad física de la fruta. Durante esa dinámica, la percepción es desplazada sucesivamente del modelo al papel y viceversa, para verificar que el diseño sea correcto y corregir eventuales errores.

Ahora bien, esa realimentación que se mantiene entre el dibujo y la manzana para lograr una representación correcta puede conseguirse aunque alguien se comiera la fruta antes de terminar el dibujo, pues se puede verificar y corregir comparándolo con lo que se sabe acerca de cómo debe lucir una manzana. No debe confundirse esta habilidad con la verificación, propia de la percepción, ni con la corrección, propia del acto motor, sino como la coordinación entre ambas.

\section{Integración visualizar-dibujar: Integración espacial motora}

Así como la percepción es fundamental cuando se dibuja un objeto presente físicamente, al intentar reproducir o copiar sobre el papel la imagen visual percibida, del mismo modo se incorpora la capacidad de visualizar cuando la imagen por trazar es mental. El resultado de ello es similar a la integración descrita por Carlson, Rowe y Curby (2013) bajo el nombre de integración visual espacial.

La integración espacial motora corresponde a la habilidad superior que integra las capacidades de visualización con las destrezas motoras durante la acción de dibujar. Actúa en presencia del objeto percibido 
o prescindiendo de este, como una referencia interna que invoca al movimiento muscular e involucra la aprehensión que supone la construcción mental de una imagen.

Para que esta integración desemboque en acción motora (dibujar), es imprescindible la coordinación visual-motora. Es decir, no podría haber coordinación visual motora sin que se manifieste antes una integración espacial motora.

Retomando el ejemplo de la manzana, quien la dibuja debe tener una correcta visión y una capacidad motora que le permita realizar los trazos y comenzar el proceso de realizar-verificar-corregir el diseño desde un plano superficial. Simultáneamente, se encuentra la aprehensión de la manzana, que ocurre en el ámbito visual de la inteligencia espacial, al visualizarla.

Esa aprehensión que invoca los movimientos musculares y se encuentra entre la inteligencia y la acción motora es la integración espacial-motora, que se une a la coordinación visual-motora y constituye un conocimiento, que Gärdenfors (2005) Ilama "implícito", el cual deviene en un saber cómo, acompañado de una abstracción de la información.

Al trazar la proyección de un objeto, quien lo dibuja pone en práctica un proceso intelectual y motor que finaliza al considerar que el trazo se corresponde satisfactoriamente con la representación visual del objeto, de tal manera la aprehensión de un objeto potencia la acción de dibujarlo, al concluir el dibujo el objeto se comprende mejor. En el logro aprehensivo se encuentra el verdadero potencial educativo del dibujo.

Dibujar, entonces, es un ejercicio para la inteligencia visual espacial, que a su vez potencia el acto de dibujar. El producto material de ello, el dibujo, es una síntesis de información plasmada en el papel y, al mismo tiempo, como producto cognitivo se obtiene una conceptualización en la mente.

\section{Integración de habilidades propiamente mentales: Codificación estructural}

Mariano Prado (2013) comenta: "Cuando el ojo y el cerebro de una persona entrenada en el dibujo procesan cognoscitivamente la información percibida se constituye una estructura, la cual es una representación más útil y productiva" (p. 97). Las palabras del investigador dejan clara la existencia de una fuerza intelectual más allá de la acción de dibujar desarrollada a través de ella y produce la estructura.

Prado (2013) define ese concepto como: "Todo aquel sistema que pueda servir de apoyo, en el intento de [...] representar cualquier forma u objeto existente en la naturaleza o en el ambiente" (p. 98).

Para este autor, la estructura de un objeto se puede dibujar y sirve de apoyo para tal efecto, por ejemplo, al trazar un cuadrado dentro del que se circunscribe un círculo. El cuadrado sirve de estructura al círculo, así como el cubo funciona estructuralmente para la esfera pero, en la práctica su información estructural no es visible, sino que ha de ser visualizada.

La habilidad para interpretar un objeto en su correcta estructuración sirve para luego dibujarlo proporcionadamente en su justa perspectiva y expresión de su tridimensionalidad, reúne las habilidades de percepción y las impulsa más allá, por medio de las capacidades de visualización; es decir, se trata de la habilidad de integración final del MIDAS. Es esencialmente mental y en este documento se le llama codificación estructural.

Otros investigadores hablan de una especial eficiencia en la codificación de la estructura de un objeto representada internamente en la memoria visual, la cual favorece la precisión de un dibujante. La describen como una representación interna de la estructura del objeto en la memoria visual, crítica a la hora de codificar la información por dibujarse (Perdreau y Cavanagh, 2014). Esta capacidad representa un modo mucho más profundo de aprehensión de un objeto que el de la integración espacial motora 
del apartado anterior; entendiéndose por profundo que relaciona primariamente destrezas mentales y que el producto de esta intelección es una cognición.

Es decir, por medio del proceso de entendimiento que la percepción y la visualización propician sobre un objeto, se puede obtener un conocimiento estructural de él con el potencial de hacerse explícito, mediante dibujos, como su principal característica. Lo anterior significa que la capacidad puede ser desarrollada y medida en el estudiantado, y que codificar estructuralmente y dibujar se potencian recíprocamente. Se demuestra cómo la práctica del dibujo, dentro de un ambiente educativo específico, puede convocar las más altas capacidades visuales-espaciales de la inteligencia.

Finalmente, el área central del esquema en este modelo significa la conjunción e interacción de las tres habilidades superiores, como el estado de mayor pericia, de manera que una persona realmente experta en el arte de dibujar es quien integra las habilidades superiores en alto grado, manejando conocimiento, experiencia y precisión.

El esquema completo del modelo incluye los productos teóricos de las tres integraciones: una cognición o conocimiento desprendido del entendimiento que favorece la integración visualizar-percibir; un dibujo de copia resultado de la integración percibir-dibujar (considerado solo teóricamente en el supuesto de que fuera posible realizarlo sin intervención de la integración espacial motora) y un dibujo imaginado, también teórico, si se presupone del todo desligado de la acción de percibir.

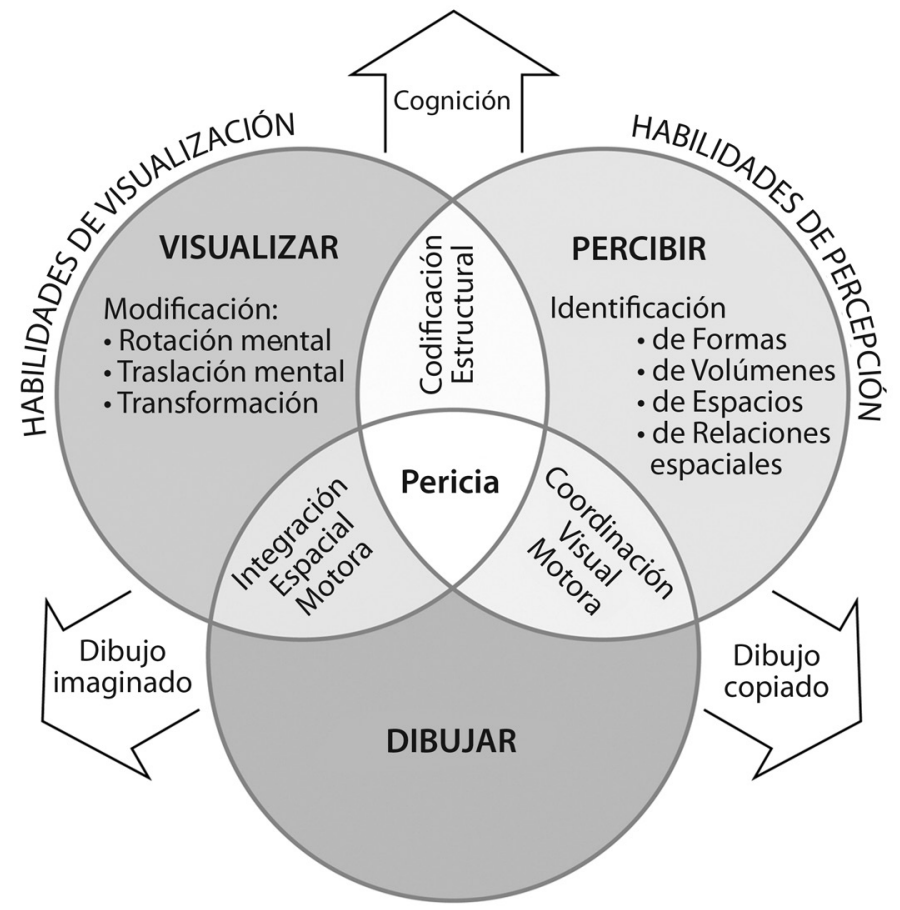

Figura 2. Modelo de interacción entre el dibujo y las actividades sensomotrices (habilidades espaciales y motrices) - MIDAS Fuente: elaboración propia con base en Calvo (2016, p. 66). 


\section{SÍNTESIS Y REFLEXIONES FINALES}

La relación del dibujo con las habilidades espaciales se examinó desde diversos ángulos y a la luz de los aportes de múltiples investigadores. Se argumentó que las habilidades perceptivas facilitan la interacción con el ambiente circundante; también que la visión permite la interpretación instantánea de la tridimensionalidad del mundo y las relaciones espaciales de los objetos visibles. Dentro de la dinámica de dibujar, la percepción se vuelve activa al prestar atención a los rasgos generales y a los detalles, con el fin de adquirir mayor información de ellos.

Mientras tanto, la visualización construye una imagen mental de un objeto y permite procesar información visual de él, tanto para traducirla a movimiento muscular como para iniciar un proceso consciente de generación de ideas. El MIDAS propone que esta adquisición de conocimientos facilita la racionalización del reporte visual, produciéndose una cognición por el tipo de análisis mental que integra las habilidades visuales espaciales.

Según lo anterior, quien dibuja inicialmente se vale de la información proveniente de procesos visuales para iniciar la actividad motriz y conducir el trazo. Entonces, a partir de la confrontación de la imagen mental con la figura gráfica que se va trazando, se realimenta su visualización y se corrige la precisión para delinear el modelo, así se obtiene un entendimiento más elevado del objeto. Se constituye un aprendizaje reducible a conocimiento estructural, el cual proviene del ámbito visual de la inteligencia espacial.

Un ejemplo de ello se muestra en la figura 1 al inicio de este documento. En ella la información estructural permanece implícita, lo que no equivale a oculta, mientras que en la figura 3 parte de esa información se muestra explícita gracias a que puede dibujarse.

El hecho de que durante este proceso se sumen la aprehensión y la generación de conocimientos y que se plasmen en un dibujo a la vez que se integre su aprendizaje, debe ser del mayor interés para la educación.

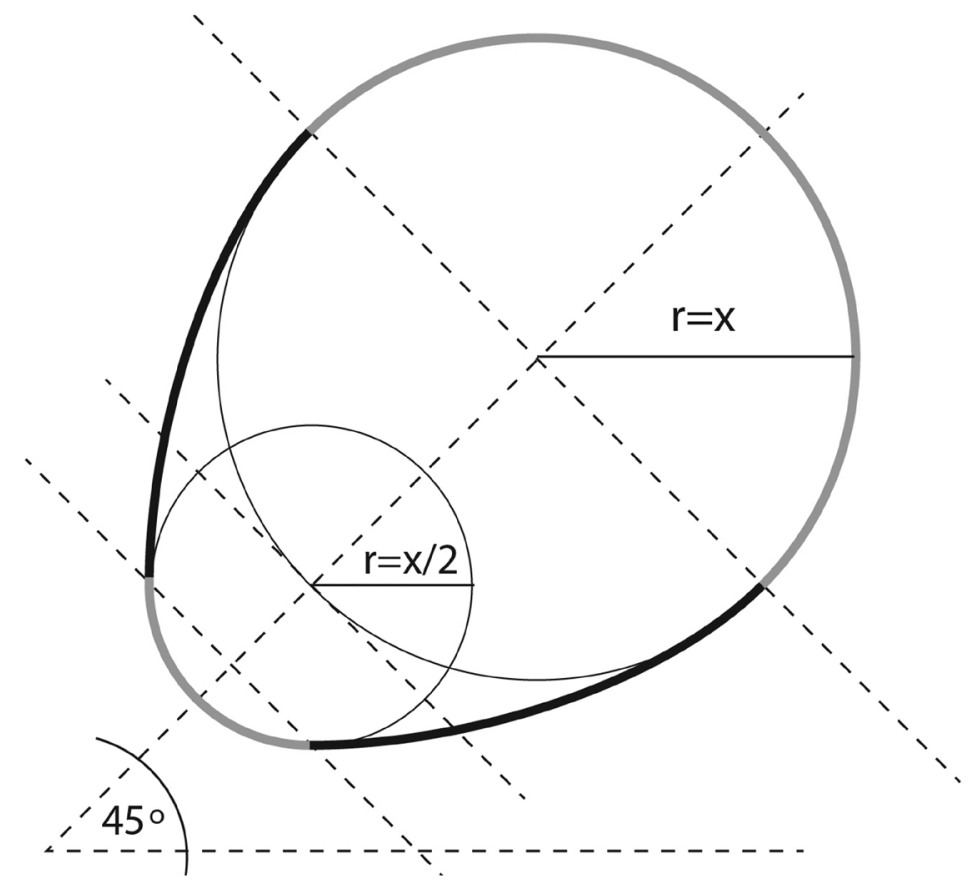

Figura 3. El contorno de la figura 1 con cierta información estructural explícita. Fuente: elaboración propia. 
Como lo muestra la figura 3, trazar sirve para plasmar información (aprendizajes) sobre el papel, pero además, dibujar se postula como una vía de fomento de la inteligencia visual- espacial en un sistema en el que este conjunto de habilidades y el dibujo se desarrollan entre sí, dinámicamente. No obstante, a pesar de su valioso potencial, el campo de la docencia no aprovecha esta visión del dibujo como potenciador de la inteligencia espacial.

Incorporar los postulados teóricos a la práctica educativa es tema para muchas otras discusiones. Lo evidente es, por ahora, que el modelo puede servir de herramienta teórica para aproximarse a una enseñanza que integre el ámbito visual de la inteligencia. Sobre esa línea de acción, la propuesta didáctica de Calvo (2016) es un esfuerzo por desarrollar las habilidades superiores de integración que se describen, sumando la teoría del MIDAS mediante la distribución de objetivos educacionales sobre cada uno de los factores de la tríada visualizar-percibir-dibujar (p. 106).

La propuesta didáctica mencionada considera el dibujo como una estrategia para desarrollar habilidades intelectuales del ámbito visual-espacial. En este sentido, de interpretación del modelo (el dibujo como medio), dibujar estimula las habilidades visuales espaciales sin importar la precisión con la que se trace, lo cual resulta determinante para el dibujo concebido como ejercicio mental, pues sus beneficios serían accesibles a todos y no solo a quienes tienen talento natural para ello. La importancia de la aseveración anterior es que se le confiere al dibujo, abordado como estrategia para la formación integral de las personas, la cualidad de ser universal.

En dirección opuesta (el dibujo como fin), se desprenden otras implicaciones: las capacidades mencionadas potencian la acción de dibujar en una espiral sin retroceso que conduce hacia la pericia y favorece la precisión, algo a lo que cualquier dibujante aspira. La idea impacta positivamente una enseñanza del dibujo tradicionalmente enfocada en la coordinación visual motora, donde se enfatizan los ejercicios de copia y la adquisición de técnicas de trazado, sombreado entre otras. La formación universitaria en dibujo ha dado un paso adelante como lo evidencia Prado (2014), al sumar el delineado de estructuras invisibles como un ejercicio que fomenta también la codificación estructural de manera empírica.

EI MIDAS viene a enriquecer el panorama, por lo que promete ser un punto de partida hacia la innovación de la metodología de enseñanza del dibujo y la integración espacial- motora. Este aporte a la teoría clama, sin embargo, por la continuidad de la investigación sobre estos temas poco explorados. Al observar el potencial formativo de sus implicaciones, que pueden extenderse a campos del saber en apariencia desemejantes como la Psicología, la Educación, la Ingeniería y las Artes Plásticas, se debe hacer un llamado a revisar el modelo y al examen científico que valide o refute sus argumentos.

\section{REFERENCIAS}

Bellido, M. (2012). Inteligencia espacial, conceptos de volumen y espacio y su representación en alumnos de Secundaria: Aplicación en las aulas. Madrid: Universidad Internacional de la Rioja.

Calvo Guevara, P. (2016). Propuesta de técnica de dibujo a mano alzada con énfasis en el desarrollo de habilidades del ámbito visual de la inteligencia espacial en estudiantes de noveno año del Liceo Santa Gertrudis de Grecia, durante el 2016. (Tesis de Licenciatura). Universidad Estatal a Distancia, San José, Costa Rica.

Carlson, A., Rowe, E. y Curby, W. T. (2013). Disentangling Fine Motor Skills' Relations to Academic Achievement: The Relative Contributions of Visual-Spatial Integration and Visual-Motor Coordination. [Desenredando la relación de las destrezas motoras finas con el logro académico: las contribuciones relativas de la integración visual espacial y la coordinación motora visual]. The Journal of Genetic Psychology, 174(5), 514-533. 
Gärdenfors, P. (2005). La intuición como conocimiento implícito. Revista de Filosofía Univ. de Costa Rica, XLIII (108), 51-55, enero-abril, 2005. San José, Ed. UCR.

Gardner, H. (2001). Estructuras de la mente: La teoría de las inteligencias múltiples. (6a reimp.). Bogotá: Fondo de Cultura Económica Ltda.

Hoffman, D. D. (2000). Visual intelligence: How we create what we see [Inteligencia visual: Cómo creamos lo que vemos] pp. 1-46. Recuperado de http://seniorseminarsp2011.qwriting.qc.cuny.edu/ files/2011/02/Hoffman-chpts-1-and-2.pdf

Koffka, K. (1922). Perception: An introduction to the Gestalt-theorie [Percepción: una introducción a la teoría Gestalt]. [Recurso de internet por Green C., York University, Toronto, Ontario. Original publicado en Psychological Bulletin (19), 531-585] Recuperado de http://psychclassics.yorku.ca/Koffka/ Perception/perception.htm

Mohler, J. (2008). A review of spatial ability research [Una Revisión de la investigación sobre habilidad espacial]. Engineering Design Graphics Journal (EDGJ). 72 (2), 19-30. Recuperado de http://www.edgj. org/index.php/EDGJ/article/viewFile/49/48

Mujica, A. (2012). Estrategias para estimular el dibujo en los estudiantes de educación inicial. Revista de Investigación. 77(36).

Newell, A., Shaw, J. y Simon, H. (1958). The process of creative thinking [El proceso del pensamiento creativo]. Recuperado de: http://www.rand.org/content/dam/rand/pubs/papers/2008/P1320.pdf

Paz, J. (2013). Una propuesta de estrategia didáctica para elproceso enseñanza-aprendizaje del dibujo técnico. Revista Dilemas Contemporáneos: Educación, Política y Valores. [Artículo no.2], 1(1).

Perdreau, F. y Cavanagh, P. (2014). Drawing skill is related to the efficiency of encoding object structure [La habilidad para dibujar se relaciona con la eficiencia para codificar la estructura del objeto]. I-Perception. 5(2), 101-119.

Piaget, J. (1969). Psicología y Pedagogía. Recuperado de http://dspace.universia.net/ bitstream/2024/1249/1/PiagetJeanPsicologiayPedagogia.pdf

Piaget, J. e Inhelder, B. (1997). Psicología del niño. [14a ed.] Madrid: Ed. Morata, S. L.

Prado, M. (2013). La adquisición de actitudes, aptitudes y conceptos estructurales: una disciplina imprescindible para el aprendizaje del dibujo. Revista Comunicación. 12, 2 (23), 96-112.

Richey, R. [ed.] (2000). The legacy of Robert M. Gagne [El legado de Robert M. Gagné]. New York, ERIC.

Sorby, S. (1999). Developing 3-D Spatial Visualization Skills. [Desarrollando destrezas de visualización espacial 3D]. Engineering Design Graphics Journal. 63(2), 21-32. Recuperado de http://www.edgj.org/ index.php/EDGJ/article/viewFile/126/122

Sorby, S. (2007). Developing 3D spatial skills for engineering students [Desarrollando las destrezas espaciales 3D para estudiantes de ingeniería]. Australian Journal of Engineering Education. 13(1). Recuperado de http://www.engineersmedia.com.au/journals/aaee/pdf/AJEE_13_1_Sorby.pdf

Triola, M. (2007). Estadística para las ciencias sociales [Trad. M. Leticia Esther Ayala]. México: Pearson Educación.

Velásquez, B. y León, A. (2011). ¿Cómo la estrategia de mapas mentales y conceptuales estimulan el desarrollo de la inteligencia espacial en estudiantes universitarios? Tabula Rasa 15, 221-254. ISSN 1794-2489.

Wertheimer, M. (1923). Laws of organization in perceptual forms [Leyes de organización en las formas perceptuales]. A source book of gestalt psychology. 71-88. London: Routledge y Kegan Paul. Recuperado de http://psychclassics.yorku.ca/Wertheimer/Forms/forms.htm 